\title{
A System Designed to Convert Plastic Waste Product into Utilitarian Arti- facts
}

\author{
Dr. Duong Vu, Duy Tan University-Vietnam \\ Prof. Ashfaq Ahmed P.E., Purdue University Northwest
}

Ashfaq Ahmed is a Professor of Electrical and Computer Engineering Technology at Purdue University Northwest. Ahmed received his bachelor's of science degree in electrical engineering from the University of Karachi in 1973 and master's of applied science degree in 1978 from University of Waterloo. He is the author of a textbook on power electronics, published by Prentice-Hall. He is a registered Professional Engineer in the state of Indiana. He is a senior member of IEEE. Ahmed's current interests include embedded system design, electric vehicle, and VHDL design.

\section{Prof. Omer Farook, Purdue University Northwest}

Omer Farook is a member of the faculty of Electrical and Computer Engineering Technology at Purdue University, Nothwest. Farook received the diploma of licentiate in mechanical engineering and B.S.M.E. in 1970 and 1972, respectively. He further received B.S.E.E. and M.S.E.E. in 1978 and 1983, respectively, from Illinois Institute of Technology. Farook's current interests are in the areas of embedded system design, hardware-software interfacing, digital communication, networking, image processing, and biometrics, C++, Python, PHP and Java languages. He has a keen interest in pedagogy and instruction delivery methods related to distance learning. He has a deep commitment to social justice and in achieving economic and educational equity. 


\title{
A System Designed to Convert Plastic Waste Product into Utilitarian Artifacts
}

\begin{abstract}
The paper expounds a senior design project that was undertaken to convert plastic waste into utilitarian artifacts. The paper presents here the practice followed by the authors in their respective Department of Electrical Engineering Technology at Duy Tan University, Da Nang, Vietnam and Purdue University Northwest, Hammond, Indiana.

This paper describes the following promising solution: (a) set up and organize a system for collecting plastic used for water and soda bottles, (b) design and manufacture production line for automatically processing plastic bottles to make plastic ribbons of various sizes, (c) use the plastic ribbon to make a prototype of useful products like tables, chairs, roofing, decorations, etc.

This paper covers the design details of three machines that are core in the successful implementation of the project. The first machine converts waste plastic into plastic ribbon. The second machine is for the straightening of the plastic ribbon. The third machine is for kneading straight plastic ribbon into various artifacts of choice.
\end{abstract}

The paper brings forth the projects economic and social benefits. On the economical side, this will minimize all expenditures for waste processing related to disposition of the plastic waste, create more jobs, especially in rural areas, and providing plastic products with reasonable price for low income population. On the social side, this will improve environmental conditions, reduce landfill waste, and eliminate spreading of disease due to contamination from burning and melting of plastics. The project enhances students' awareness of ecology, and the environmental protection of community.

The pedagogy of the course delivery is based on "Interactive Learning Model”. The paper elaborates the benefits derived through the pedagogical approaches of keeping the learner actively engaged in all aspects of discovery and design. The course interactively involves the learner in directing and defining the material under discourse. The paper presents the fine points of pedagogical approach that were implemented in successful completion of this course.

\section{Introduction}

Plastic bottles find common use in a wide range of applications in our daily lives. As a result production and use of plastic bottles has increased remarkably over the years. The high demand of plastic bottles, especially in the water and soft drink industry, has brought with it severe environmental problems due to careless disposal of these bottles [1]. Statistical data reveals that yearly people add up to 8-9 million tons of plastic waste to our environment, which includes up to 40\% Poly Ethylene Terephthalate (PET), the clear plastic used for water and soda bottle containers. PET is low priced and produced in enormous quantities. The amount of plastic waste discarded into the Eastern Sea in Vietnam is about 0.28-0.73 million tons/year, which ranks 4th in the world [2]. This impacts ships safety routing and contaminates fisheries. Traditionally 
plastic waste is processed by burning or sending to a land fill. The impact of burning one ton of hard waste creates about 62 cubic meters of methane, which is equivalent to one ton $\mathrm{CO}_{2}$ [3]. The constant buildup of plastic waste in landfills has become a major source of concern for many sectors of sustainable society. Massive pollution contaminates rivers and clogs drainage systems, usually ending up in the oceans due to people's negligence. 450 years are needed to initiate the decomposition of PET [4]. And it needs additional 50 - 80 years more to completely decompose. $\mathrm{CO}_{2}$ gas pollutes the environment, and plastic waste affects landmasses and oceans. The next section discusses a promising environmentally friendly solution for reducing pollution by recycling plastic bottles.

\section{Solution}

The concept was proposed as a senior design project idea by Professor - Dr. Duong Vu. The capstone senior design course pedagogy enforced interactive learning utilizing the methodology of Outcome Based Education (OBE) [5]. OBE's end result is the students' design projects are presented at the end of the course. The course is conducted in a lab or studio setting that integrates both lecture and laboratory work in the same environment. The course interactively developed student's understanding of: the product design process, project management skills, and engineering practice principles while keeping track of the economic aspects of the design. The team based approach provided students with the opportunity to discuss alternative design ideas and work on their communication and interpersonal skills [6]. In addition, the setup of this course also played an important role in meeting ABET general Criteria, Criterion 3 Student Outcomes a -k. The course covers (a, b, c, d, e, f, g, h, k) [7].

Essentially, recycling and re-manufacturing would allow production of new products with lower material inputs than would otherwise be required. Recycling can therefore decrease energy and material usage to produce new goods and creating less waste and pollution. The Energy efficient plastic recycling process involved a complex system of machines and new manufacturing practices. The process of recovering waste plastic and reprocessing into useful products was designed to be implemented in three stages:

I. Set up and organize a system for collecting plastics used for water and soda bottles.

II. Design and manufacture a production line for automatically processing plastic bottles to make plastic ribbons of various sizes.

III. Use the plastic ribbon to manufacture prototypes of useful artifacts and products like tables, chairs, roofing material, decorations, etc.

A successful plastics recycling operation requires a dependable source of plastic waste and an efficient collection and separation system. A group of four senior students kicked off Phase I of the project by setting up four stations to collect plastic bottles in rural areas (Hoa Vang dis/Da Nang city). To encourage participation in the process, the consumers were employed and involved in the process. This also strengthens and enhances a sense of community ownership, and involvement. Each household is provided with a green bin for collecting plastic waste and paid a cash amount for their effort. 
In Phase II of the senior design project, a set of machines were designed and developed by the students at Duy Tan University, Da Nang, Vietnam. These machines are available for converting the Polyethylene Terephthalate (PET), the clear plastic waste, into plastic ribbons. The Ribbon Cutting Machine presented in Figure 1 is the block diagram representation of the prototype machine for the purpose of shredding the recycled plastic bottles into the respective widths of plastic ribbons. The ribbons in turn are woven into scores of useful artifacts.

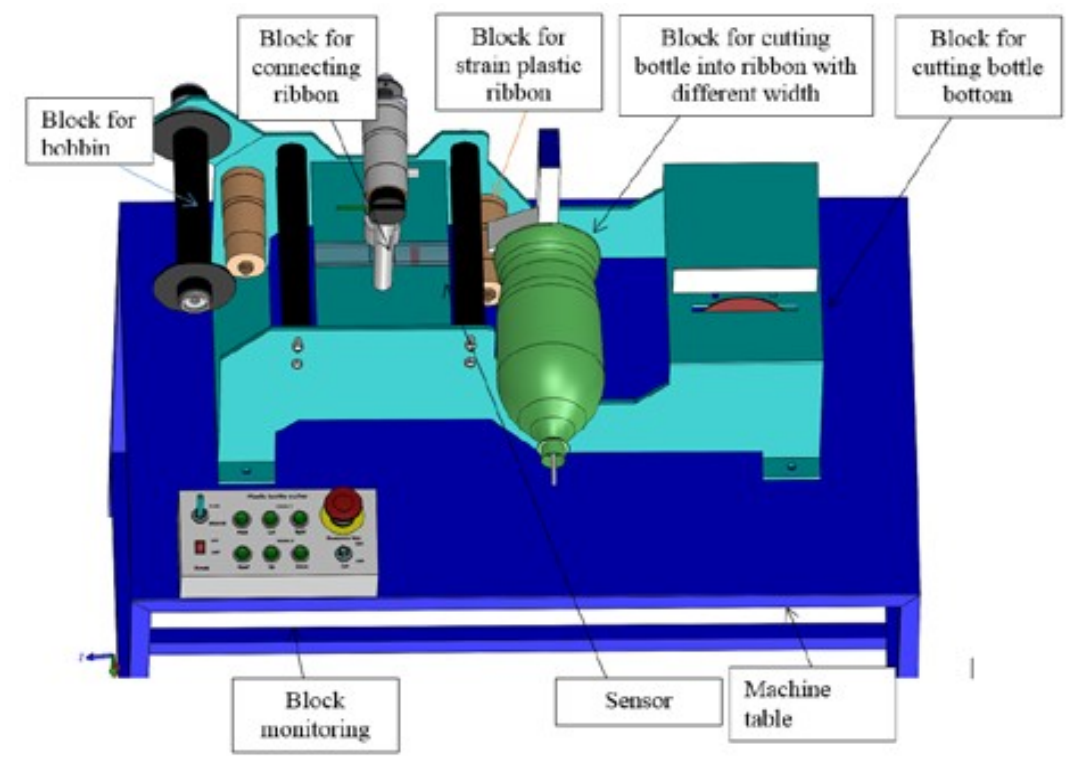

Figure 1. Block Diagram of the Ribbon Cutting Machine

The entire design project was divided into multiple tasks of more or less of the same complexity. Each team was responsible for one task. Figure 2 shows a physical prototype of the machine designed and manufactured by the senior design students at Duy Tan University, Da Nang, Vietnam for recycling plastic bottles.

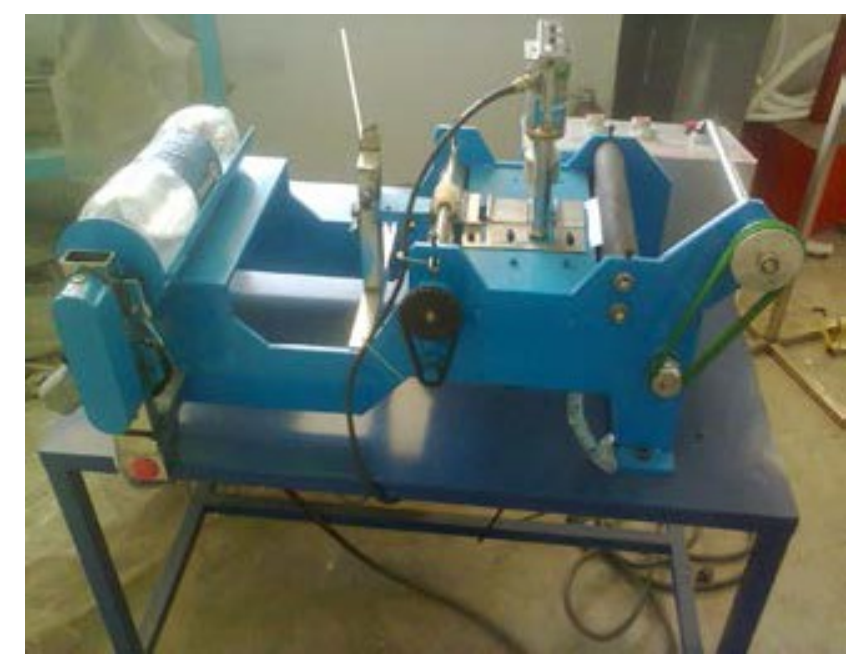

Figure 2. Cutting Bottles into Ribbon and Connecting them Continuously 
The manufacturing of the artifacts were not part of the senior design course completion requirement, however, students began using the plastic ribbons to make recycled plastic products during final week of their course. The end product and artifacts shown in Figure 3 have been tested as samples in the prototype machines and are ready for deployment for recycling plastic bottles.

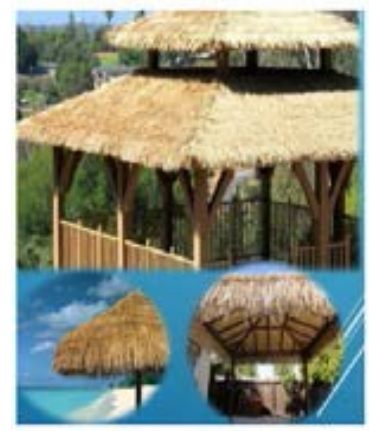

Roof

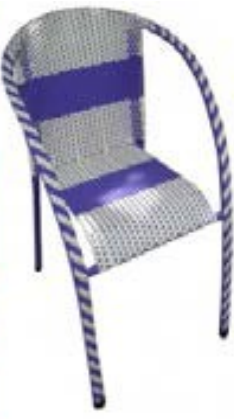

chair

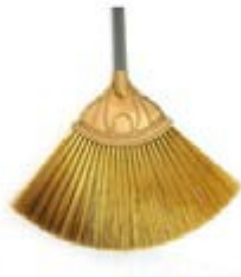

Broom

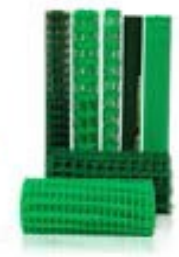

Carpet

Figure 3. Some Product Made of Recycling plastic Ribbon

\section{Interactive Learning Model Pedagogy}

The pedagogy of the course is based on Outcome Based Education (OBE), which is learner driven and aimed at achieving outcomes. The basic principle of OBE is that everyone can learn at their own pace, provided the necessary resources that are allocated towards learning. The instructor is simply a facilitator, and a mentor inspiring creativity, self-paced learning and critical thinking. By the end of the senior design course, each student should achieve the desired outcome. The senior design project is aptly suited for this purpose. The project is pursued by dividing the senior design class into a number of teams. The advantage of breaking the class into teams provides an environment that lends itself to horizontal learning. The students take ownership of the learning process and it is self-directed, however, the course instructor directs in understanding the design process and ensures that students complete their project in a timely manner. They learn by interactively engaging in the process, making their own inquires, and validating or rejecting the theoretical concepts that either apply or do not apply in their specific context. They deal with the contents rather than with abstract concepts. Concepts are utilized within the scope of specific context.

\section{Makeup of the team}

The senior design class with an enrollment of twenty (20) students is broken into four teams with five students in each team. To maintain functional consistency among different teams, the team members were selected based on their backgrounds, interests, and experience. In the first meeting, the instructor explained the project to be worked on, discussed the project's objectives/goals and asked the students to think about what role they would like to play on the project team. Typical roles selected by students are team lead person, who will maintain proper resource allocations, and every member of the team would have the responsibility to be a technical member of the team. 


\section{Assessment}

A self-assessment of the senior capstone design course was conducted by the responsible faculty. A set of performance criteria (see Table 1) based on previously conceived models [6] was utilized to verify that specific learning outcomes were met. For example, ABET Criteria 3. Student Outcome d ( an ability to design systems, components, or processes for broadly-defined electrical engineering technology problems appropriate to program educational objectives) was assessed using the following performance indicators:

\begin{tabular}{|l|c|}
\hline Performance Indicator & Index Weight \\
\hline Defines customer needs & $12 \%$ \\
\hline Defines design constraints & $8 \%$ \\
\hline Offers alternative solutions & $8 \%$ \\
\hline Defines problems to be solved & $12 \%$ \\
\hline Defines project scope & $10 \%$ \\
\hline Compares alternative solutions & $6 \%$ \\
\hline Defends selection of final design & $10 \%$ \\
\hline Build prototype to meet needs & $12 \%$ \\
\hline Validates performance of prototype & $10 \%$ \\
\hline Cost effectiveness & $12 \%$ \\
\hline
\end{tabular}

Table 1. Performance Indicators

The format used for evaluation and assessment follows the outline presented in [8]. Team performance, timely execution, and oral and written communication skills were measured based on weekly progress reports, project display and demonstration. To effectively measure the quality of individual team work in the group project, each team was assessed based on their contribution to the final product- product assessment. In order to assess effectiveness of individual teamwork skills and interaction and cooperation with the other design team, the group process was also assessed - process assessment [9]. The group performance was translated into individual grades.

\section{Conclusions}

The senior capstone design experience provided students the opportunity to apply what they have learned in their undergraduate courses in previous years into a viable project. It bridges the gap between classroom and industry and allows students to apply their knowledge and skills to tackle real world challenges. It gives them the responsibility and freedom to perform at their own pace and learn to interact and communicate with their team mates. The studio / lab learning environment provides them a learning platform that is beyond the boundaries of the classroom and prepares them for the industry. Additionally, this experience provides the concerned faculty to think beyond the confines of the class room and allow them to address engineering solutions for the betterment of life. 


\section{References}

[1] J. Hopewell, R. Dvorak, and E. Kosior, "Plastics recycling: challenges and opportunities," Philosophical Transactions of the Royal Society B Biological Sciences, Jul 2009.

[2] C. Kieule, S. Emilie, and P. Morgane, "Life cycle of floating debris in the canals of Ho Chi Minh city," horizon.documentation.ird.fr, November 2016.

[3] Working paper of Urban Development Management Support Centre - PADDI, https://en.wikipedia.org/wiki/Incineration

[4] https://www.thebalance.com > ... > Sustainable Businesses > Resources

[5] O. Farook and C. Sekhar and J. Agrawal and E. Bouktache and A. Ahmed, "Outcome based education and assessment,” ASEE 2006 Annual Conference \& Exposition, Chicago, Illinois. June 2006.

[6] J. R. Goldberg, "Senior design capstone courses and ABET outcomes," IEEE Engineering in Medicine and Biology Magazine, July/August 2006.

[7] Criteria for Accrediting Engineering Technology Programs, 2-16-2017. ABET, Inc.

[8] S. Beyerlein, D. Davis, M. Trevisan, P. Thompson. And K. Harrison, “Assessment Framework for Capstone Design Courses,” ASEE Annual Conference, 2006.

[9] Lejk, M. et al. A Survey of Methods of Deriving Individual Grades from Group Assessments. In Assessment \& Evaluation in Higher Education. Vol. 21, No. 3, 1996. 